\title{
VARIAÇÃO NICTEMERAL DE PARÂMETROS FÍSICO-QUÍMICOS E BIOLÓGICOS DO RIBEIRÃO DAS CRUZES, ARARAQUARA-SP
}

SANTOS, Vitor Rocha. Apoio técnico do Centro de Estudos Ambientais - Ceam do Centro Universitário de Araraquara - Uniara. Mestrando da Universidade Estadual Paulista - Unesp, campus Araraquara.

COSTA, Daniel Jadyr Leite. Apoio técnico do Programa de Mestrado em Desenvolvimento Regional e Meio Ambiente do Centro Universitário de Araraquara - Uniara. Mestrando EESC/USP.

TEIXEIRA, Denilson. Professor-pesquisador do Programa de Mestrado em Desenvolvimento Regional e Meio Ambiente do Centro Universitário de Araraquara - Uniara. Rua Carlos Gomes, 1338 - Centro.

CEP 14801-340 - Araraquara-SP. E-mail: dteixeira@ uniara.com.br.

\section{RESUMO}

O uso inadequado das águas, sua degradação e distribuição desigual podem comprometer a sua quantidade e qualidade necessárias às gerações futuras, bem como gerar conflitos de interesses entre os segmentos industrial, urbano e agrícola. Nesse contexto, torna-se de grande importância a realização de estudos sobre a qualidade dos recursos hídricos, tendo como base a análise da variação temporal de parâmetros limnológicos. O presente estudo foi realizado na sub-bacia hidrográfica do ribeirão das Cruzes, que contribui para o abastecimento da cidade de Araraquara (SP) com cerca de $30 \%$ de toda água captada e servida à população. O objetivo desta pesquisa foi comparar a qualidade da água desse ribeirão a montante e a jusante do lançamento do efluente da ETE municipal em um período de 24 horas (ciclo de variação nictemeral). A coleta de dados, compreendendo o período de um dia, foi realizada com o intuito de observar a dinâmica de funcionamento e a amplitude de variação dos processos ecológicos do sistema estudado. Os parâmetros analisados apresentaram variações significativas nas seções de montante e jusante do ponto de lançamento do efluente. Com a análise nictemeral, fica evidente a influência dos efluentes sobre as águas do ribeirão das Cruzes, principalmente durante determinadas horas do dia.

Palavras-chave: Variação nictemeral; DBO; DQO.

\begin{abstract}
Improper use of water, its degradation and irregular distribution can affect the quantity and quality needed for future generations, as well as create conflicts of interest between the industrial, urban and agricultural segments. In this context, it is of great importance the realization of studies on the quality of the hydric resources based on the analysis of temporal variation of limnological parameters. This study was conducted in the sub-basin of Ribeirão das Cruzes, which contributes to the water supply of the city of Araraquara (SP) around 30\% of all water captured and offered to the population. The objective of this research was to compare the water quality of river upstream and downstream of effluent discharge from a local treatment station in a 24 hour period (diurnal cycle variation). Data collection, comprising the period of one day, was done in order to observe the dynamics of operation and range of variation of the ecological processes in the studied system. The parameters analyzed showed significant variations in the sections of the upstream and downstream from the effluent discharge. With the nictemeral analysis it is evident the influence of effluents on the the waters of Ribeirão das Cruzes, especially during certain periods of the day.
\end{abstract}

KeYwords: Nictemeral variation; BOD; COD. 


\section{INTRODUÇÃo}

A importância da água está definida por seus atributos como recurso de múltiplos usos disponíveis, sendo elemento fundamental para a manutenção da vida e do abastecimento doméstico ou agrícola, das áreas industriais e urbanas, entre outros usos. Tendo em vista a sua ampla utilização urbana e industrial, surge a consequente degradação do recurso hídrico, o que restringe os seus múltiplos usos como vital elemento e contribui para a deterioração progressiva da qualidade de vida em nossos dias. A falta e/ou escassez da água, junto com os problemas originados pelos riscos decorrentes da sua poluição, constituem a "crise da água", flagelo reconhecido hoje pelos governos do mundo (BUSTOS, 2003).

Segundo Braga et al. (2002), além dos problemas relacionados à quantidade de água como escassez, estiagens e cheias, há também aqueles relacionados à sua qualidade. Acontaminação de mananciais impede, por exemplo, seu uso para abastecimento humano, agravando o problema da escassez desse recurso.

O nível de poluição hídrica no mundo tem crescido em função de vários fatores, e principal impacto produzido no ciclo hidrológico é a elevada taxa de urbanização, com efeitos diretos e indiretos nos ecossistemas aquáticos.

Segundo Tundisi (2003), o despejo de águas residuárias de uso doméstico, não tratadas, é uma das principais causas de deterioração dos recursos hídricos em águas interiores e nas águas costeiras.

Devido ao grande número de fontes poluidoras dos recursos hídricos, faz-se de grande importância a aplicação e o aprimoramento de técnicas para tratamento de água e esgoto, além da implementação eficaz de programas de monitoramento da qualidade das águas dos corpos hídricos receptores das fontes poluidoras difusas e pontuais.

O tratamento dos efluentes é necessário para reduzir a carga poluidora pontual e, assim, minimizar os efeitos negativos ao meio ambiente. No Brasil, a quantidade de matéria orgânica removida deve atender aos padrões de lançamento e de qualidade das águas dos corpos receptores, conforme estabelecido na resolução
Conama 357/2005. A eficiência requerida para as Estações de Tratamento de Esgotos (ETE) depende da classe em que o corpo receptor está enquadrado e de sua capacidade em diluir e depurar esses poluentes.

A vazão afluente de esgotos sanitários das ETE dos municípios geralmente não é constante, há variações no decorrer do tempo. Para Von Sperling (2005), a geração de esgotos de uma localidade varia ao longo do dia (variações horárias), ao longo da semana (variações diárias) e ao longo do ano (variações sazonais).

Dessa maneira, os esgotos sanitários podem sofrer variações de vazão horárias, em que a vazão das águas residuárias segue a curva de consumo da água de abastecimento público, com defasagem de algumas horas (OLIVA, 1997).

Tsutiya e Sobrinho (2000) apresentam gráficos da vazão da produção de esgotos domésticos em função do tempo para alguns municípios do Estado de São Paulo. Verifica-se claramente a variação horária de vazão e os diferentes comportamentos das curvas resultantes, de acordo com o porte do município.

Geralmente os sistemas de tratamento de esgotos municipais não possuem etapas que objetivem a equalização da vazão de saída, o que permite a ocorrência de variação do volume de esgotos a serem lançados nos corpos receptores em função do tempo. Devido a esse aspecto, torna-se importante o monitoramento do lançamento das cargas poluidoras e da qualidade das águas dos corpos receptores com amostragens horárias, durante um período de 24 horas. Este tipo de monitoramento está fundamentado emum ciclo chamado de variação nictemeral.

Os estudos sobre a variação nictemeral de parâmetros limnológicos básicos são considerados de grande importância para o entendimento do metabolismo de ecossistemas aquáticos tropicais (SILVA, 1980; ESTEVES et al., 1988; TOLEDO et al., 1988; BOZELLI et al., 1990; CAMARGO, 1991). Outros autores (BARBOSA, 1981; MELACK \& FISHER, 1983; CAMARGO \& MIYAI, 1988) argumentam que a dinâmica de ecossistemas aquáticos tropicais pode ser mais fortemente influenciada por 
variações nictemerais do que por variações sazonais.

Entretanto, muito pouco se conhece a respeito dos padrões nictemerais das variáveis limnológicas em ecossistemas lóticos tropicais, particularmente no Brasil, e suas implicações em estudos ecológicos. Dentre os raros estudos em ambientes lóticos brasileiros, pode-se mencionar o de Camargo et al. (1995), que analisaram a variação nictemeral de alguns parâmetros limnológicos em dois pequenos rios da região estuarina de Cananeia (NECCHI Jr. et al, 1996).

Miwa (2007) avaliou o funcionamento do sistema de tratamento de esgotos de Cajati, Vale do Ribeira de Iguape (SP), em diferentes épocas do ano, sendo uma das escalas de amostragem o ciclo nictemeral. $\mathrm{O}$ estudo mostra que os pulsos de vazão que chegam ao sistema podem causar variações na qualidade do efluente final.

Sendo assim, o objetivo do presente trabalho é analisar a variação nictemeral de variáveis físicoquímicas e biológicas, indicadoras da qualidade das águas, durante um período chuvoso. Foram realizadas comparações da qualidade da água de um ribeirão, a montante e jusante do ponto de lançamento do efluente da estação de tratamento de esgotos do município de Araraquara, SP.

\section{Material e MÉTODos}

\section{Área de estudo}

A análise da qualidade das águas foi realizada em um trecho do ribeirão das Cruzes, onde foram definidos dois pontos de coleta, sendo um a montante e outro a jusante do ponto de lançamento da ETE municipal. A sub-bacia hidrográfica do ribeirão das Cruzes, localizada na cidade de Araraquara (SP), possui uma área aproximada de $192,6 \mathrm{~km}^{2}$, da qual $37,2 \mathrm{~km}^{2}$ (ou 19,3\% da área total) está ocupada atualmente por área urbana. A sub-bacia está inserida na Bacia Hidrográfica TietêJacaré, definida como Unidade de Gerenciamento de Recursos Hídricos 13 (UGRHI-13). A sub-bacia e os pontos de coleta podem ser visualizados no mapa contido na Figura 1.

Responsável por mais de 30\% do abastecimento público de Araraquara (SP), de acordo como Decreto
Estadual n. ${ }^{\circ} 10755 / 77$ (CETESB, 1977), o ribeirão das Cruzes está enquadrado como classe 2 até a represa de captação de água para abastecimento público, e como classe 4 desta seção (jusante da represa) até a confluência com o rio Jacaré-Guaçú, de acordo com o Decreto Estadual n. ${ }^{\circ}$ 10755/77 (CETESB, 1977).

Utilizando o método de regionalização hidrológica, a partir de dados do Sistema de Informações para o Gerenciamento de Recursos Hídricos do Estado de São Paulo (SIGRH, 2010), o ribeirão das Cruzes possui uma vazão média para o ponto de lançamento do efluente de $4.392 \mathrm{~m}^{3} / \mathrm{hora}$.

O efluente da estação de tratamento de esgoto possui uma vazão média de $1.622 \mathrm{~m}^{3} / \mathrm{hora}$, segundo dados do Departamento Autônomo de Águae Esgotos de Araraquara (DAAE, 2006).

O município trata $100 \%$ dos $97 \%$ de efluentes coletados com uma eficiência de $75 \%$. Considerandose o potencial de carga poluidora, que é de $10.229 \mathrm{kgDBO} / \mathrm{dia}$, há um remanescente de 2.787 $\mathrm{kgDBO} / \mathrm{dia}$, que éliberado no ribeirão das Cruzes (CETESB, 2008).

\section{Metodologia de coleta}

As amostras de água foram coletadas nos dias 26 e 27 de janeiro de 2006, em uma campanha de coleta horária, em um período de monitoramento de 24 horas. Foram determinados 2 pontos diferentes para a coleta das amostras, um a montante e o outro a jusante do lançamento da ETE, para análises imediatas e posteriores de indicadores físico-químicos e microbiológicos.

As análises imediatas (em campo) foram realizadas com uma sonda multiparâmetros YSI, modelo 556. As análises posteriores foram realizadas no Laboratório de Análises Químicas e Controle Industrial, do Centro Tecnológico da Fundação Paulista (Laci-Cetec) de Lins (SP). As coletas microbiológicas de coliformes totais e fecais foram realizadas com uma frequência de duas horas.

Para o efluente foram realizadas análises dos mesmos parâmetros, porém as coletas ocorreram com 
uma frequência de seis horas, totalizando quatro amostragens no período de monitoramento. Todas as coletas foram realizadas com luvas plásticas e o material coletado foi conservado em caixas térmicas com gelo.

As análises foram realizadas conforme procedimento descrito nas normas técnicas da Companhia Ambiental do Estado de São Paulo - CETESB e Associação
Brasileira de Normas Técnicas - ABNT. Os procedimentos laboratoriais de microbiologia foram realizados segundo os padrões descritos na 19. a edição do Standard Methods for the Examination of Water and Wastewater da American Public Health Association (APHA, 1995). Os parâmetros e métodos de análise correspondentes estão descritos na Tabela 1.

Tabela 1 - Parâmetros e métodos de análise utilizados na pesquisa.

\begin{tabular}{|c|c|}
\hline PARÂMETROS & MÉTODOS \\
\hline Temperatura & \multirow{2}{*}{ Sonda YSI - Modelo 556 } \\
\hline Oxigênio dissolvido (OD) & \\
\hline Condutividade elétrica & \\
\hline Nitrito $\left(\mathrm{NO}_{2}^{-}\right)$ & \\
\hline Nitrato $\left(\mathrm{NO}_{3}^{-}\right)$ & \\
\hline Nitrogênio Kjeldahl (NTK) & \multirow{2}{*}{ Laci-Cetec } \\
\hline Demanda química de oxigênio (DQO) & \\
\hline Demanda bioquímica de oxigênio (DBO) & \\
\hline Sólidos totais dissolvidos & \\
\hline Fósforo & \\
\hline Coliformes totais & \\
\hline Coliformes fecais & \\
\hline &
\end{tabular}

\section{Resultados E Discussão Temperatura}

Além da variação horária da temperatura, que foi maior no período vespertino em relação aos demais, foi observada uma variação entre os pontos a montante e a jusante do ponto de lançamento da ETE, provavelmente causada devido à entrada do efluente neste trecho, o qual possui as temperaturas mais elevadas, como pode ser visualizado na Figura 2.

Observa-se que o horário em que o corpo de água atingiu as maiores temperaturas foi por volta das 17h. De forma quase semelhante, em um estudo realizado por Necchi Jr. et al. (1996) no córrego Barra Funda, localizado no município de São José do Rio Preto (SP), as maiores temperaturas foram atingidas por volta das 16 horas nas estações de inverno, primavera e outono; e por volta das 14 horas na estação do verão.

\section{Condutividade Elétrica}

Os valores de condutividade elétrica refletem a capacidade da água em conduzir corrente elétrica, e indicam a quantidade de íons presentes na água. Normalmente, as concentrações de íons em locais onde existem emissões industriais e urbanas são altas.

Os valores de condutividade elétrica encontrados a jusante foram mais elevados quando comparados aos encontrados a montante, devido, provavelmente, à entrada do efluente da ETE, como pode ser visualizado na Figura 3. As concentrações mínimas a jusante foramobservadas no período da manhã, entre 9 e 10 horas, e as máximas, entre 18 e 21 horas. 


\section{Sólidos Totais Dissolvidos (STD)}

A determinação da concentração de STD na água indica a presença de metais, sais inorgânicos, óleos e graxas e matéria orgânica. Elevadas concentrações desse parâmetro podem levar a um aumento da Demanda Bioquímica de Oxigênio (DBO) e da Demanda Química de Oxigênio (DQO), e a uma diminuição da concentração de oxigênio dissolvido(OD), evidenciando também processos de contaminação da água.

A concentração do parâmetro STD não apresentou variação no ponto a montante durante o período analisado. No ponto a jusante, os valores encontrados variaram pouco, sendo mais elevada a jusante, devido, provavelmente, à entrada do efluente da ETE no corpo hídrico.

\section{Oxigênio Dissolvido(OD), Demanda Bioquímica de Oxigênio (DBO) e Demanda Química de Oxigênio (DQO)}

$\mathrm{O}$ oxigênio dissolvido (OD) é um dos mais importantes parâmetros para avaliar as condições de um ambiente aquático, uma vez que é indispensável nos processos metabólicos dos seres vivos.

Segundo Esteves (1988), a concentração de oxigênio na água depende de fatores físicos, como a difusão na interface ar-atmosfera e a turbulência na água; fatores químicos, como os processos de oxidação de substâncias inorgânicas reduzidas; e de fatores biológicos, como a fotossíntese (que libera oxigênio na água) e a respiração dos organismos, associada à oxidação bioquímica da matéria orgânica por microrganismos.

Ainda deve ser mencionada a relação entre a quantidade de oxigênio dissolvido e a matéria orgânica no sistema, podendo esta última ser de origem natural ou antropogênica (CAMPAGNA, 2005).

O parâmetro OD apresentou a montante e a jusante valores mínimos às 21 horas, com concentrações de $5,9 \mathrm{mg} / \mathrm{Le} 5,1 \mathrm{mg} / \mathrm{L}$, respectivamente; e valores máximos às $5,6 \mathrm{e} 9$ horas a montante $(7,2 \mathrm{mg} / \mathrm{L}) \mathrm{e} 9$ horas a jusante $(6,5 \mathrm{mg} / \mathrm{L})$. No efluente, o valor mínimo foi observado às 6 horas, com concentração de 4,6mg/L; e o valor máximo às 12 horas, com concentração de 5,3mg/L (Figura 5).
Considerando que as coletas foram realizadas durante a estação do verão, além da temperatura, as concentrações mínimas de OD também tiveram comportamento semelhante às amostragens realizadas por Necchi Jr. et al. (1996). De acordo comos autores, o valor de menor concentração de OD durante a estação de verão para o córrego Barra Funda ocorreu por volta das 22 horas.

As alterações nos valores de OD devem-se à variação temporal da carga de matéria orgânica lançada no rio pela ETE. Apesar disso, as concentrações de OD no rio são superiores a $2 \mathrm{mg} / \mathrm{L}$ em qualquer amostra, que é o limite estabelecido pela resolução Conama 357/05 para rios enquadrados na classe 4 .

As concentrações de DBO apresentam valores relativamente altos a jusante, indicando elevadas concentrações de matéria orgânica biodegradável, o que pode prejudicar a oxigenação da água e a manutenção da vida aquática. Os resultados das análises de DBO e DQO, em geral, colaboram com a interpretação das análises de oxigênio dissolvido, pois foram observadas significativas diferenças de concentrações de OD entre os pontos a montante e a jusante, demonstrando, novamente, a influência do efluente no corpo receptor.

Além disso, como se pode observar na Figura 5 (a e b), quando há uma depleção na concentração de oxigênio dissolvido, há concomitantemente um aumento da DBO e DQO, o que indica poluição por matéria orgânica no trecho analisado.

\section{Nitrogênio e Fósforo}

A influência do lançamento dos efluentes da ETE no corpo hídrico também pode ser observada quando considerados os indicadores do processo de eutrofização. Elevadas concentrações dos parâmetros nitrogênio e fósforo podem gerar o desenvolvimento de fitoplâncton e zooplâncton no meio, levando ao início desse processo.

$\mathrm{O}$ nitrogênio pode ser encontrado nas águas na forma de nitrogênio orgânico, amoniacal $\left(\mathrm{NH}_{3} \mathrm{ou}\right.$ $\left.\mathrm{NH}_{4}^{+}\right)$, nitrito $\left(\mathrm{NO}_{2}^{-}\right)$e nitrato $\left(\mathrm{NO}_{3}^{-}\right)$. As duas primeiras chamam-se formas reduzidas ou Nitrogênio 
Total Kjeldahl (NTK) e as duas últimas, formas oxidadas.

De acordo com Von Sperling (2007), as formas predominantes do nitrogênio no esgoto bruto são o nitrogênio orgânico e o amoniacal (NTK). Para efluentes de estações de tratamento que não favorecem a nitrificação, as características são semelhantes; no entanto, apresentam a forma orgânica $\left(\mathrm{NH}_{3}\right) \mathrm{em}$ menores concentrações.

As análises realizadas a jusante do ponto de lançamento do efluente apresentaram predominantemente as formas reduzidas (NTK) do nitrogênio. As diferenças entre as concentrações das formas oxidadas do nitrogênio $\left(\mathrm{NO}_{2}^{-}\right.$e $\left.\mathrm{NO}_{3}^{-}\right)$, da montante para a jusante do ponto de lançamento, foram nulas. Por isso, na Figura 6 estão apresentadas apenas as concentrações de nitrogênio na sua forma reduzida.

O fósforo geralmente é o fator limitante da produtividade primária, e incrementos artificiais nas concentrações podem indicar poluição, sendo que águas residuárias domésticas (particularmente contendo detergentes), efluentes industriais e fertilizantes (este último proveniente de escoamento superficial) contribuem para a elevação dos níveis do composto nas águas superficiais.

As análises de Fósforo Total e Nitrogênio Total Kjeldhal (NTK) apresentaram grande variação entre os pontos a montante e a jusante, principalmente com relação ao NTK, que obteve a jusante, às 23 horas, concentração máxima, com 13,2mg/L.

Os valores obtidos para o Fósforo Total a jusante foram todos superiores a $2 \mathrm{mg} / \mathrm{L}$.

Essas diferenças de concentrações se deve à mistura do efluente no corpo de água. Concentrações elevadas desses nutrientes podem transformar o corpo hídrico numa potencial fonte de contribuição para o desenvolvimento de processos de eutrofização em ambientes lênticos que venham se localizar à jusante do ponto de lançamento.

\section{Coliformes totais e fecais}

A determinação da concentração dos coliformes assume importância como parâmetro indicador da possibilidade de existência de microrganismos patogênicos, responsáveis pela transmissão de doenças de veiculação hídrica, como febre tifoide, febre paratifoide, desinteria bacilar e cólera.

O número de coliformes totais e, principalmente, coliformes fecais na água, é um forte indicativo das condições sanitárias do meio, e serve como indicador de contaminação por esgoto sanitário. As quantidades encontradas fornecem subsídios sobre a origem e a intensidade da contaminação.

Como os valores encontrados para os coliformes totais e fecais foram muito próximos, na Figura 7 estão apresentados apenas os valores encontrados para os indicadores sanitários de coliformes totais.

Verificou-se grande variação dos valores entre os pontos de coleta a montante e a jusante. A jusante os valores foram de 20 vezes a 250 vezes maiores do que aqueles encontrados a montante, comprovando mais uma vez a influência do efluente proveniente da ETE no meio aquático.

\section{Conclusão}

Apesar da ETE do município de Araraquara (SP) ser capaz de remover mais de $80 \%$ da carga de DBO de seu efluente, atendendo aos limites de lançamento estabelecidos no Decreto Estadual n. ${ }^{\circ}$ 8468/76 (CETESB, 1976), ainda há o lançamento da carga remanescente nas águas do ribeirão, o que pode comprometer a qualidade de suas águas, principalmente durante o período de estiagem (ou estação seca), que abrange os meses de março a agosto.

Diante dos resultados obtidos, verifica-se a importância da análise nictemeral para estudos em corpos de água. Comesta análise ficou evidente a influência da ETE sobre as águas do ribeirão da Cruzes, principalmente quando são despejadas maiores cargas de poluentes durante determinadas horas do dia.

De todas as variáveis analisadas no presente trabalho, a resolução CONAMA 357/2005 estabelece padrões de qualidade de água apenas para o oxigênio dissolvido, o que abre janelas para o desenvolvimento de um quadro crítico de poluição deste corpo de água e o comprometimento das espécies que vivem neste meio. 
Dessa maneira, torna-se importante a realização do reenquadramento do ribeirão das Cruzes, por parte do comitê de bacias, sendo que esse tipo de ação está presente nas metas do Plano de Bacia (2008) da UGRHI Tietê-Jacaré.

\section{Agradecimentos}

Os autores agradecem o Laci-Cetec de Lins-SP e o DAAE de Araraquara-SP.

\section{REFERÊNCIAS}

APHA. Standard Methods for the Examination of Water and Wastewater. 19. ed. Washington: American Public Health Association, 1995.

BARBOSA, F. A. R. Variações diurnas (24 horas) de parâmetros limnológicos básicos e da produtividade primária do fitoplâncton na lagoa Carioca - Parque Florestal do Rio Doce, $M G$, Brasil. Dissertação - (Programa de PósGraduação em Ecologia e Recursos Naturais Doutorado - Universidade Federal de São Carlos, UFSCar), 1981.

BOZELLI, R.L. et al. Dinâmica nictemeral dos principais nutrientes inorgânicos e clorofila $a$ em duas lagoas costeiras fluminenses. Acta Limnológica Brasileira, v.2, p.319-343, 1990.

BUSTOS, M. R. L. A Educação Ambiental sob a ótica da Gestão de Recursos Hídricos, 2003, 194f. Tese (Doutorado em Engenharia Hidráulica e Sanitária), Escola Politécnica da Universidade de São Paulo, São Paulo, 2003.

BRAGA, B. et al. Introdução à Engenharia Ambiental: O desafio do desenvolvimento sustentável. São Paulo: Prentice Hall, 2002. 305p.

BRASIL, 2005. Resolução CONAMA 357/2005. Dispõe sobre a classificação dos corpos de água e diretrizes ambientais para seu enquadramento, bem como estabelece as condições e padrões de lançamento de efluentes, e dá outras providências. Ministério do Meio Ambiente. Disponível em: <http://www.mma.gov.br>. Acesso em: 14 de janeiro de 2006.

CAMARGO, A.F.M.; BINI, L.M.; PRADO, S.E.R. Variação nictemeral de alguns parâmetros limnológicos em dois ecossistemas lóticos do litoral sul paulista. Oecologia brasiliensis, v.1, p. 75-85, 1995.

CAMARGO, A.F.M.; MIYAI, R.K. Dinâmica do nitrogênio e do fosfato em uma lagoa marginal do rio Mogi-Guaçu (Lagoa do Pato, SP). Tese (Doutorado em Ecologia e Recursos Naturais), Universidade Federal de São Carlos, São Carlos, 1991.

CAMPAGNA, A. F. Toxidade dos sedimentos da Bacia Hidrográfica do Rio Monjolinho (São Carlos, SP): ênfase nas substâncias cobre, aldrin e heptacloro. Dissertação (Mestrado Engenharia de Alimentos). Universidade de São Paulo, Pirassununga, 2005.

CETESB - Companhia Ambiental do Estado de São Paulo. Decreto n. ${ }^{\circ} 8.468$ de 8 de setembro de 1976. Diário Oficial do Estado de São Paulo. São Paulo, 1976. 106p.

CETESB - Companhia Ambiental do Estado de São Paulo. Decreto n. ${ }^{\circ} \mathbf{1 0 . 7 5 5}$ de 22 de novembro de 1977. Diário Oficial do Estado de São Paulo. São Paulo, 1977. 12p.

CETESB - Companhia Ambiental do Estado de São Paulo. Relatório de Qualidade das Águas Interiores do Estado de São Paulo. 2008. 528p.

DAAE - Departamento Autônomo de Água e Esgotos de Araraquara, SP. Relatório Técnico: Aspectos construtivos e operacionais da 
Variação nictemeral de parâmetros físico-químicos...

estação de tratamento de esgotos da cidade de Araraquara. 2006.

ESTEVES, F.A. et al. Variação diária (24 horas) de temperatura, $\mathrm{O} 2$ dissolvido, $\mathrm{pH}$ e alcalinidade em duas lagoas costeiras do estado do Rio de Janeiro e suas implicações no metabolismo desses ecossistemas. Acta Limnológica Brasileira, v. 11, p. $99-127,1988$.

MELACK, J. M. \& FISHER, T. R. Diel Oxygen Variations and Their Ecological Implications in Amazon Floodplain Lakes. Archiv fur Hydrobiologie, Stuttgart, v. 98, n. 4, p. 422-442, 1983.

MIWA, A.C.P. Avaliação do funcionamento do sistema de tratamento de esgoto de Cajati, Vale do Ribeira de Iguape (SP), em diferentes épocas do ano, 2007, 212f. Tese (Doutorado em Engenharia Hidráulica e Saneamento), Escola de Engenharia de São Carlos da Universidade de São Paulo, São Carlos, 2007.

NECCHI JR., O.; BRANCO, L.H.Z.; BRANCO, C.C.Z. Análise nictemeral e sazonal de algumas variáveis limnológicas em um riacho no noroeste do estado de São Paulo. Acta Limnológica Brasileira, v. 8, p.169-182, 1996.

OLIVA, L.C.H.V. Tratamento de esgotos sanitários com reator anaeróbio de manta de lodo (UASB) protótipo: desempenho e respostas dinâmicas às sobrecargas hidráulicas, 1997. Dissertação - (Doutorado em Hidráulica e Saneamento), Escola de Engenharia de São Carlos da Universidade de São Paulo, São Carlos, 1997.

SIGRH - Sistema de Informações para o
Gerenciamento de Recursos Hídricos do Estado de São Paulo. Regionalização Hidrológica do Estado de São Paulo, 2010. Disponível em: <http://www.sigrh.sp.gov.br>. Acesso em: 16 de março de 2010.

SILVA, V.P. Variações diurnas de fatores ecológicos em quatro lagos naturais do "Pantanal Matogrossense" e seu estudo comparativo com dois lagos do Amazônia central e um lago artificial (represa do Lobo, "Broa", São Carlos, SP), 1980, 281f. Dissertação (Mestrado em Ecologia e Recursos Naturais), Universidade Federal de São Carlos, São Carlos, 1980.

VON SPERLING, M. Princípios do tratamento biológico de águas residuárias. Belo Horizonte: Departamento de Engenharia Sanitária e Ambiental, UFMG. 3 ed., vol.1, 2005. 452 p.

VON SPERLING, M. Estudos e modelagem da qualidade da água de rios. Belo Horizonte:

Departamento de Engenharia Sanitária e Ambiental, UFMG. v. 7, 2007. 588p.

TOLEDO, L.G.; FREITAS, J.S.; FERREIRA, C.J.A.Variações diurnas de parâmetros limnológicos no lago Paranoá, Brasília - DF., Brasil. Acta limnológica brasileira, v. 2, p. 219-237, 1988.

TSUTIYA, M. T.; SOBRINHO, P. A. Coleta e transporte de esgoto sanitário. 5 ed. São Paulo: Departamento de Engenharia Hidráulica e Sanitária da Escola Politécnica da Universidade de São Paulo, 547 p., 2000.

TUNDISI, J.G. Água no Século XXI - Enfrentando a Escassez. São Carlos: Rima, 2003. 248p.

RECEBIDO EM 21/10/2010

ACEITO EM 14/12/2010 

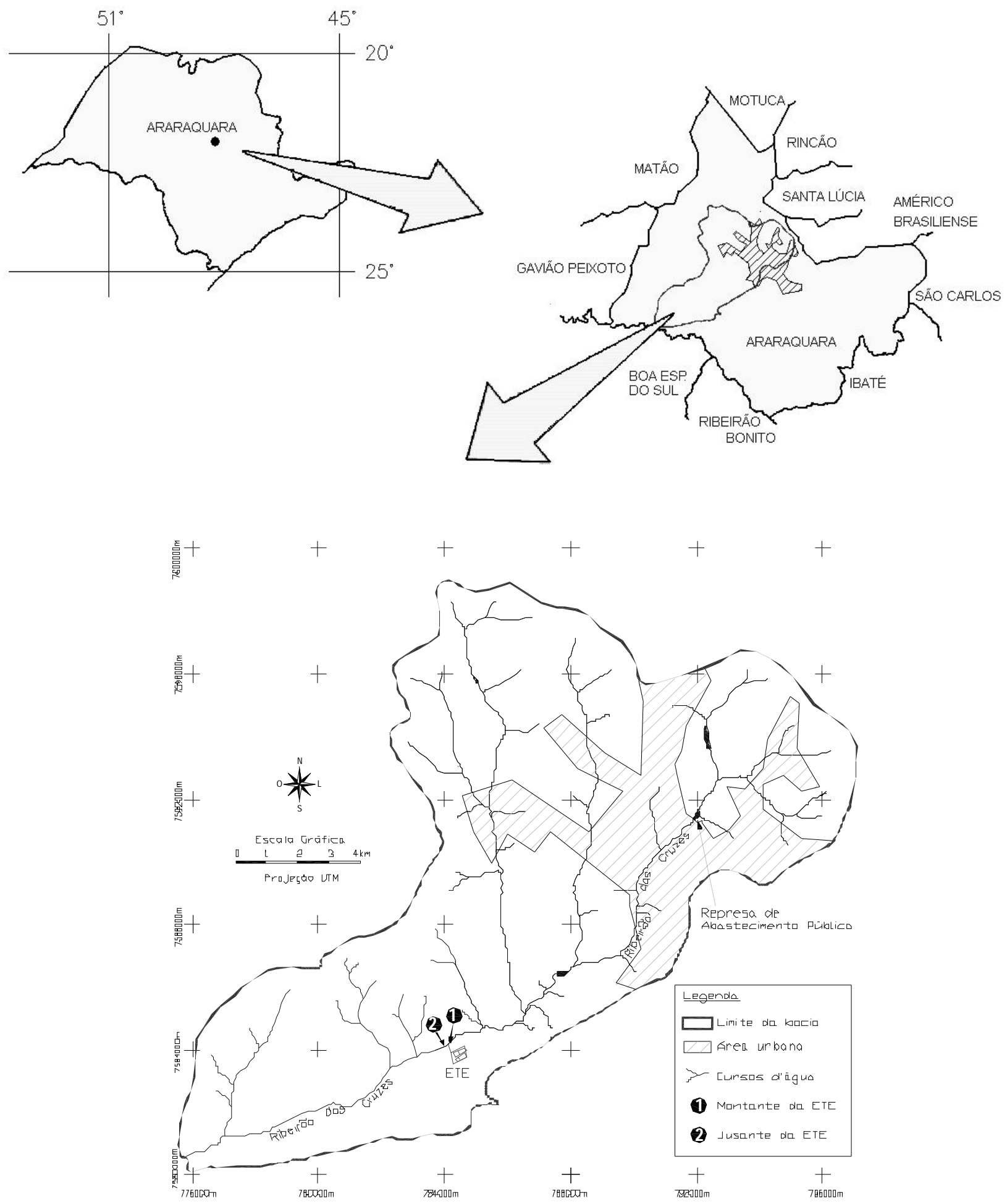

Figura 1 - Localização da sub-bacia do ribeirão do Ouro e dos pontos de coleta a montante e jusante da Estação de Tratamento de Esgotos (ETE) de Araraquara (SP).

Fonte: Dados de pesquisa. 
Variação nictemeral de parâmetros físico-químicos...

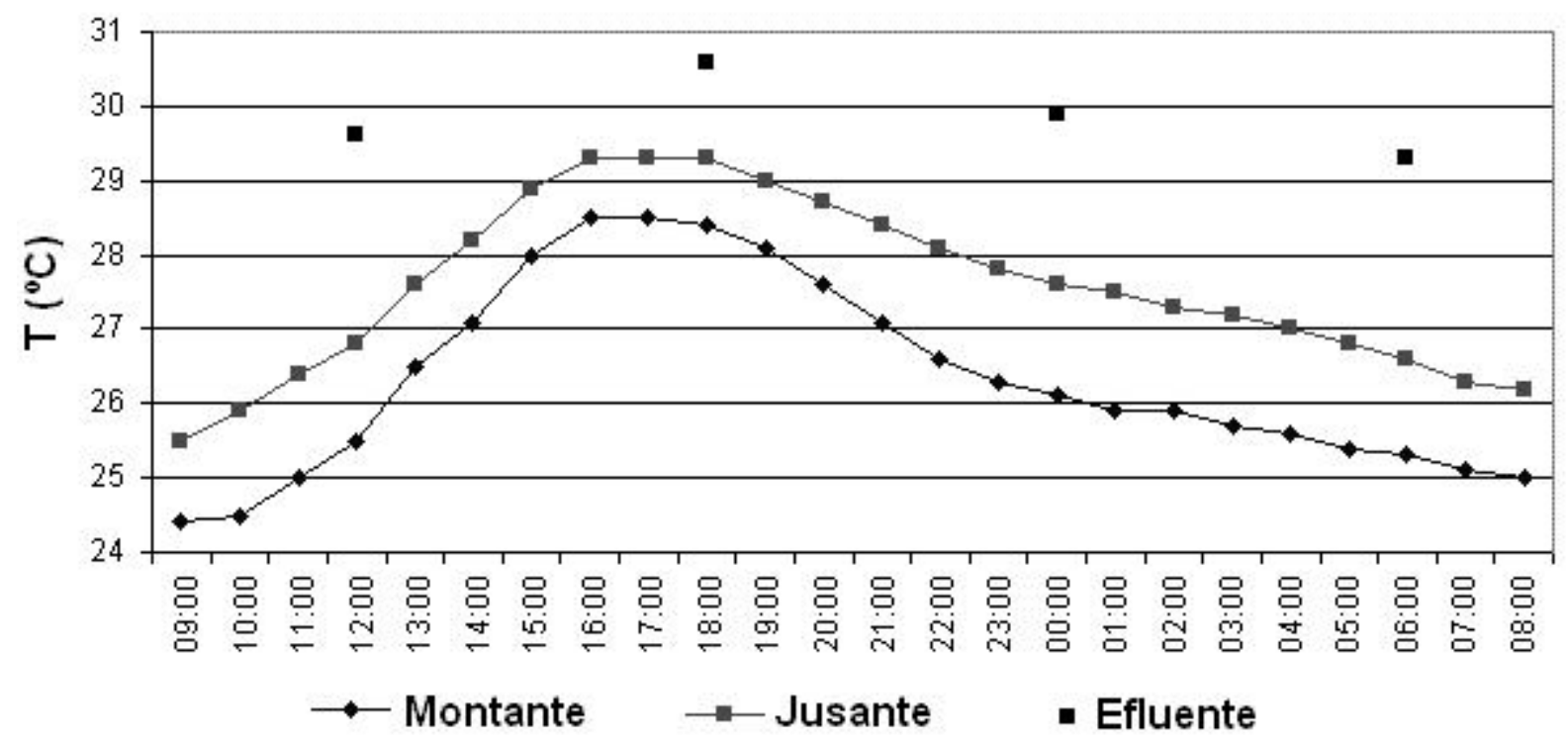

Figura 2 - Variação nictemeral da temperatura no efluente e a montante e jusante de seu ponto de lançamento.

Fonte: Dados de pesquisa.

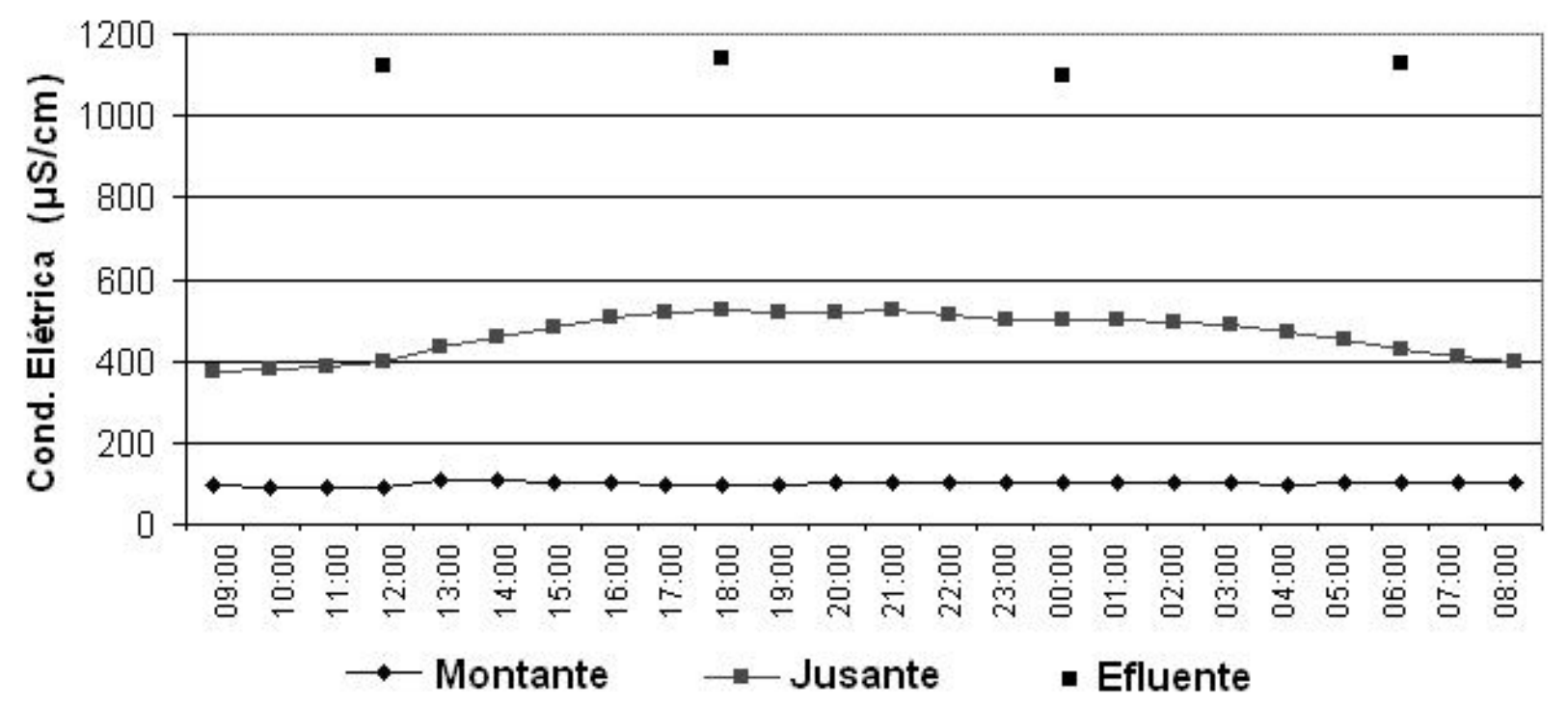

Figura 3 - Variação nictemeral da condutividade elétrica no efluente e a montante e jusante de seu ponto de lançamento.

Fonte: Dados de pesquisa. 


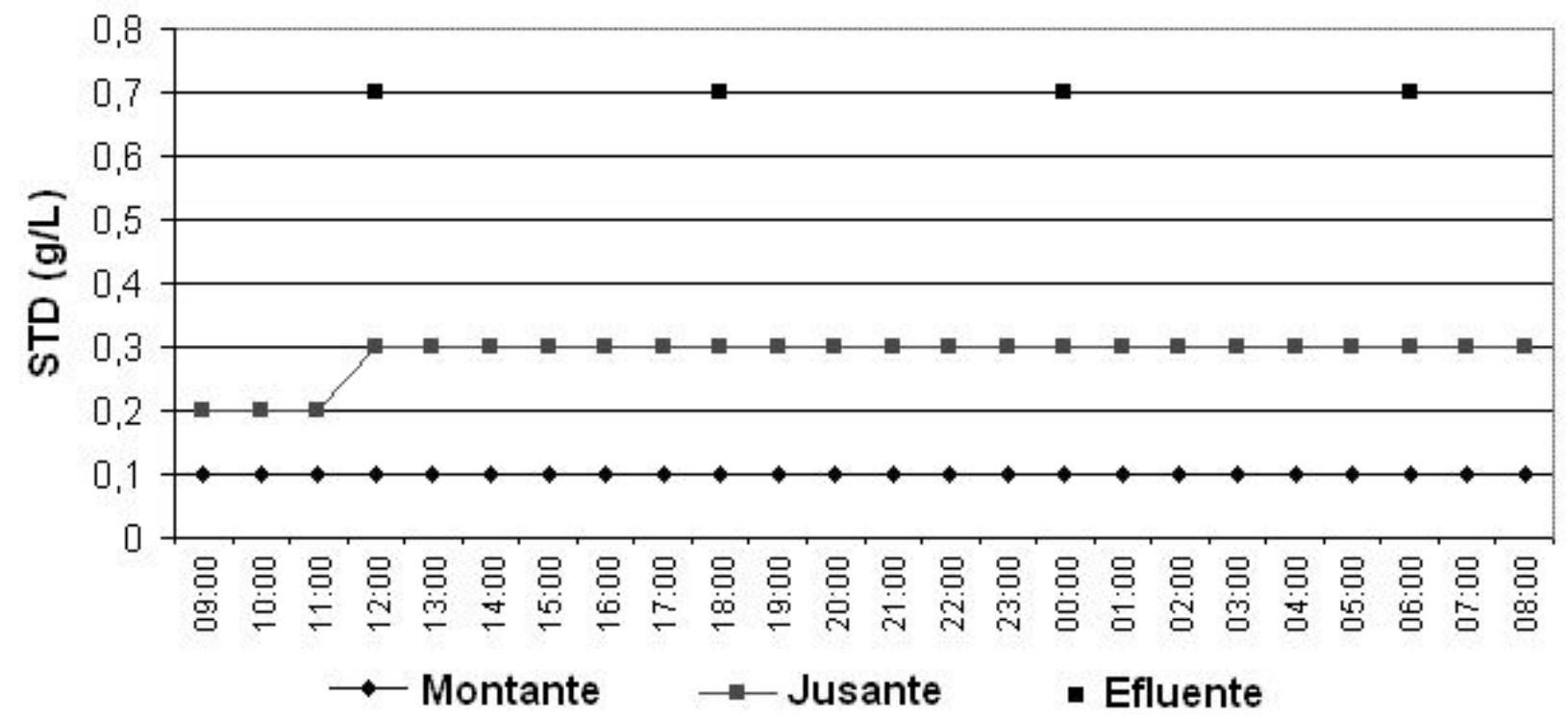

Figura 4 - Variação nictemeral dos STD no efluente e a montante e jusante de seu ponto de lançamento. Fonte: Dados de pesquisa. 
Variação nictemeral de parâmetros físico-químicos...

\section{Montante}

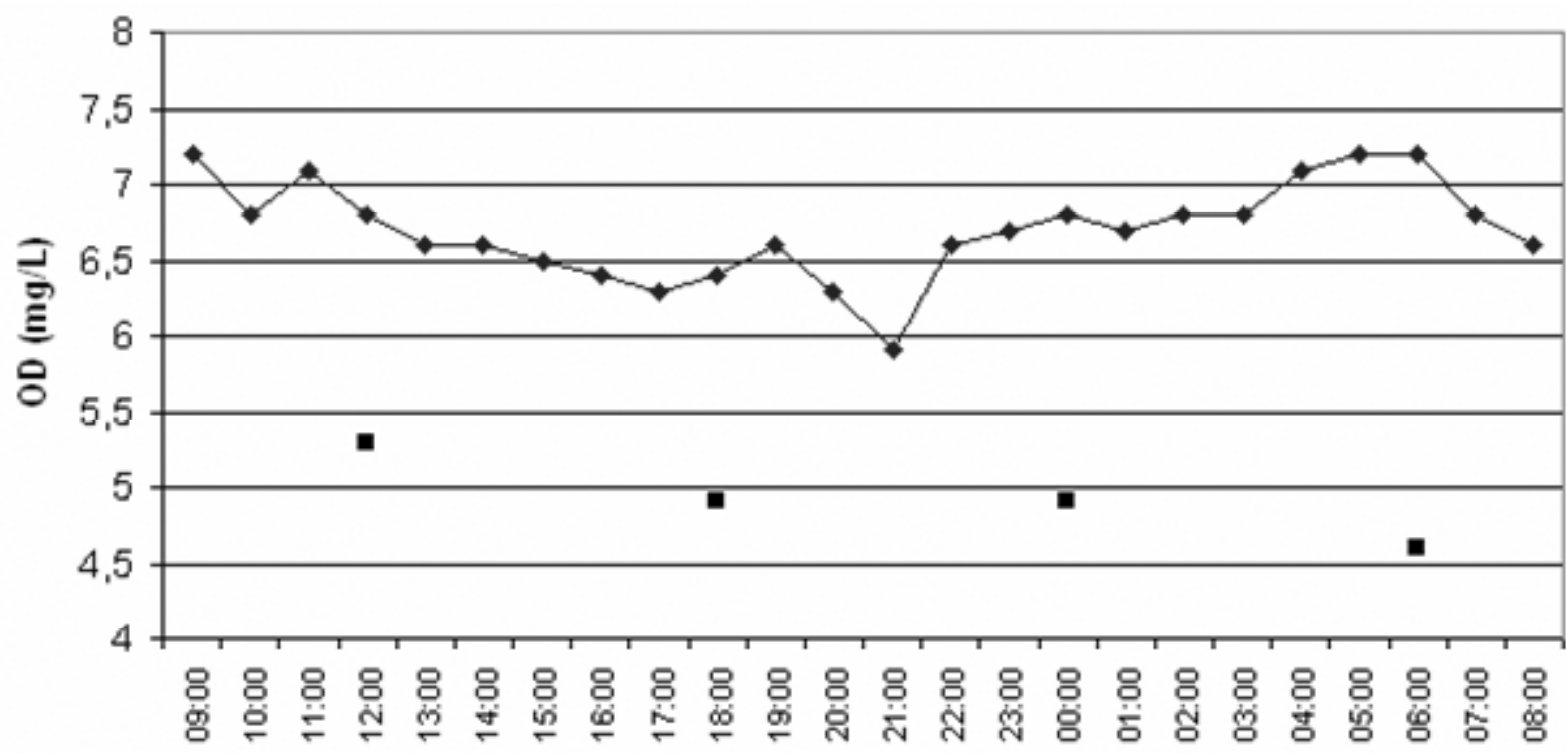

- Efluente

\section{Jusante}

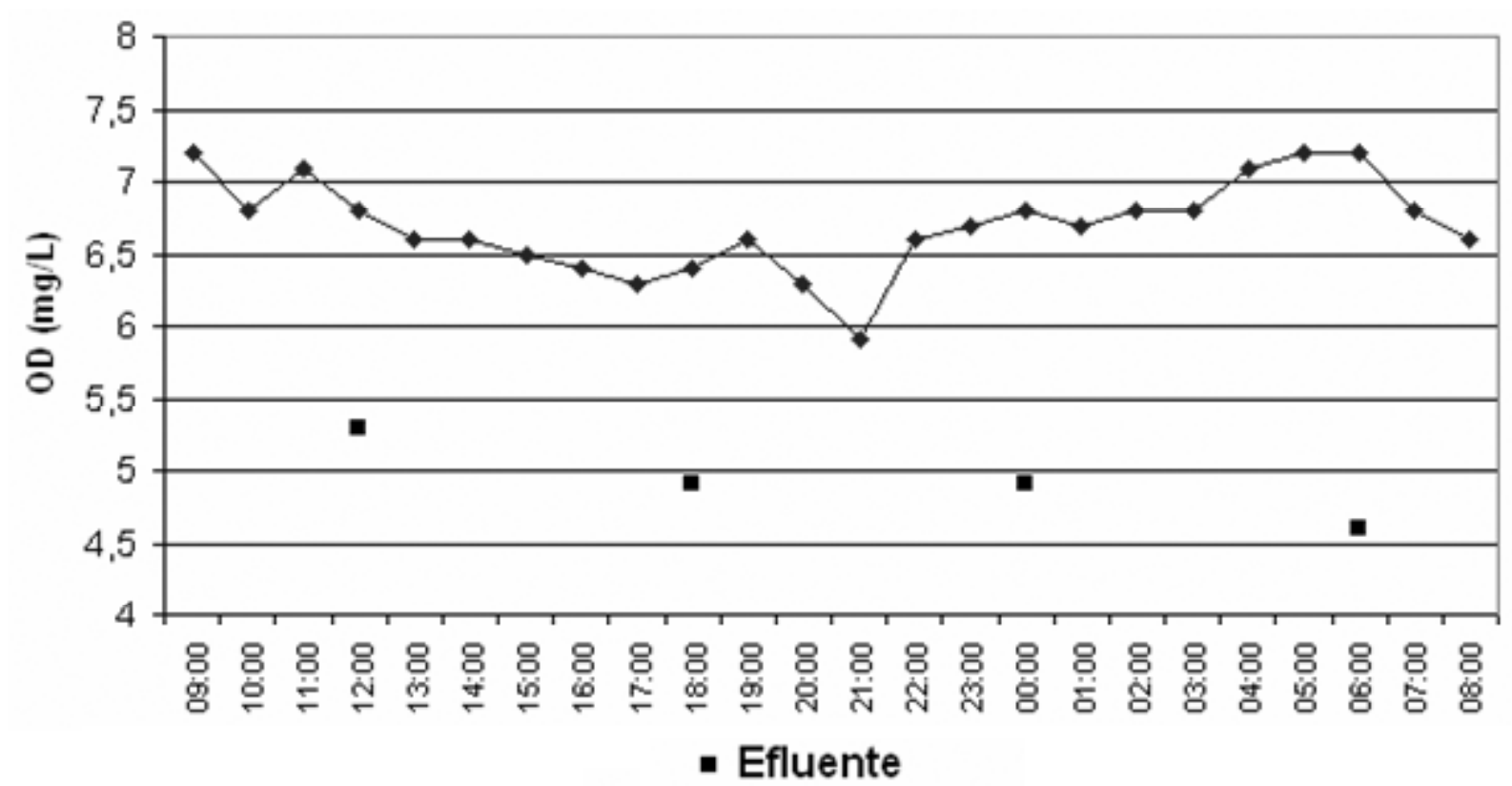

Figura 5a - Variação nictemeral do OD no efluente e a montante e jusante de seu ponto de lançamento. Fonte: Dados de pesquisa. 


\section{Montante}

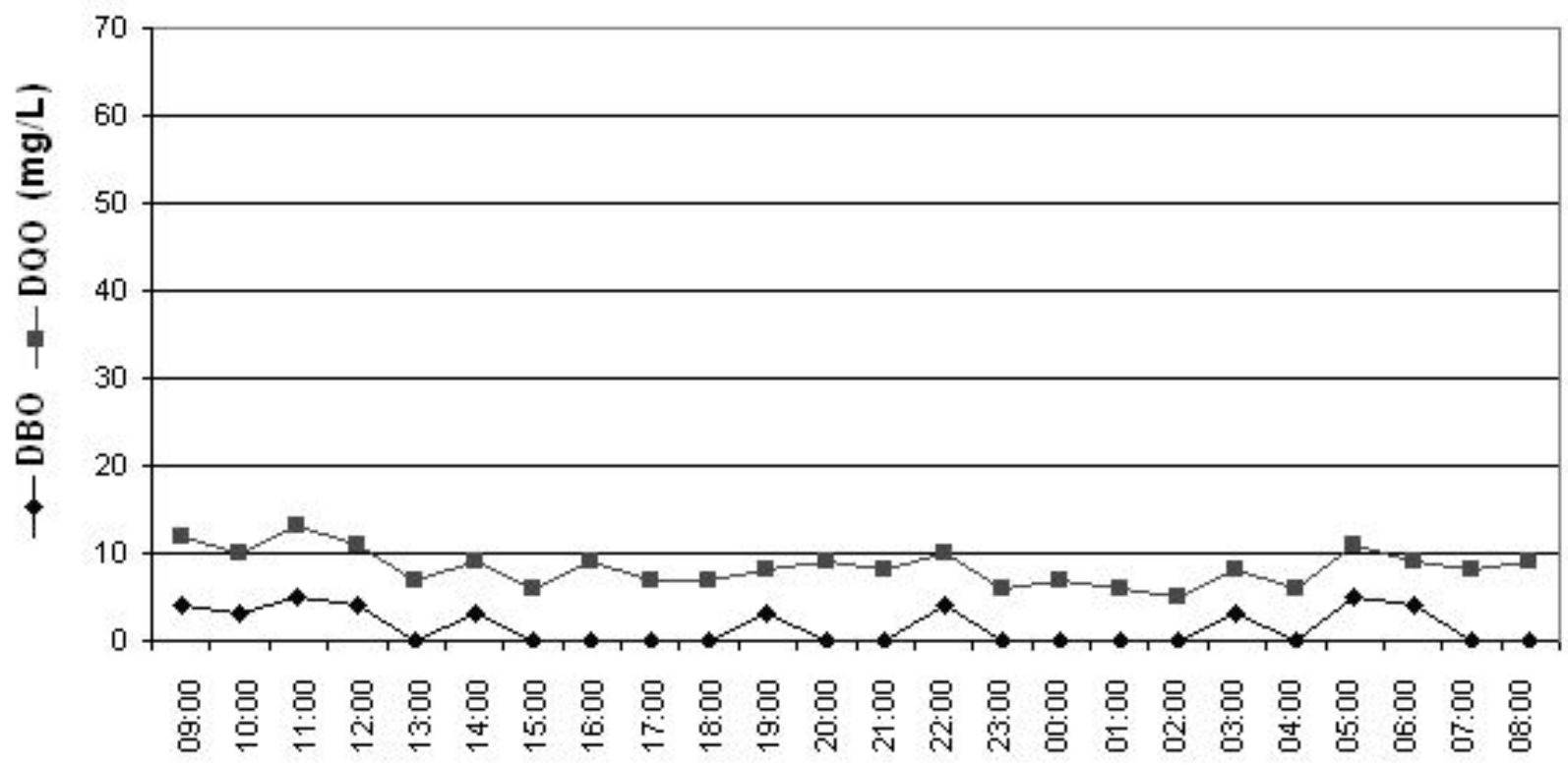

\section{Jusante}

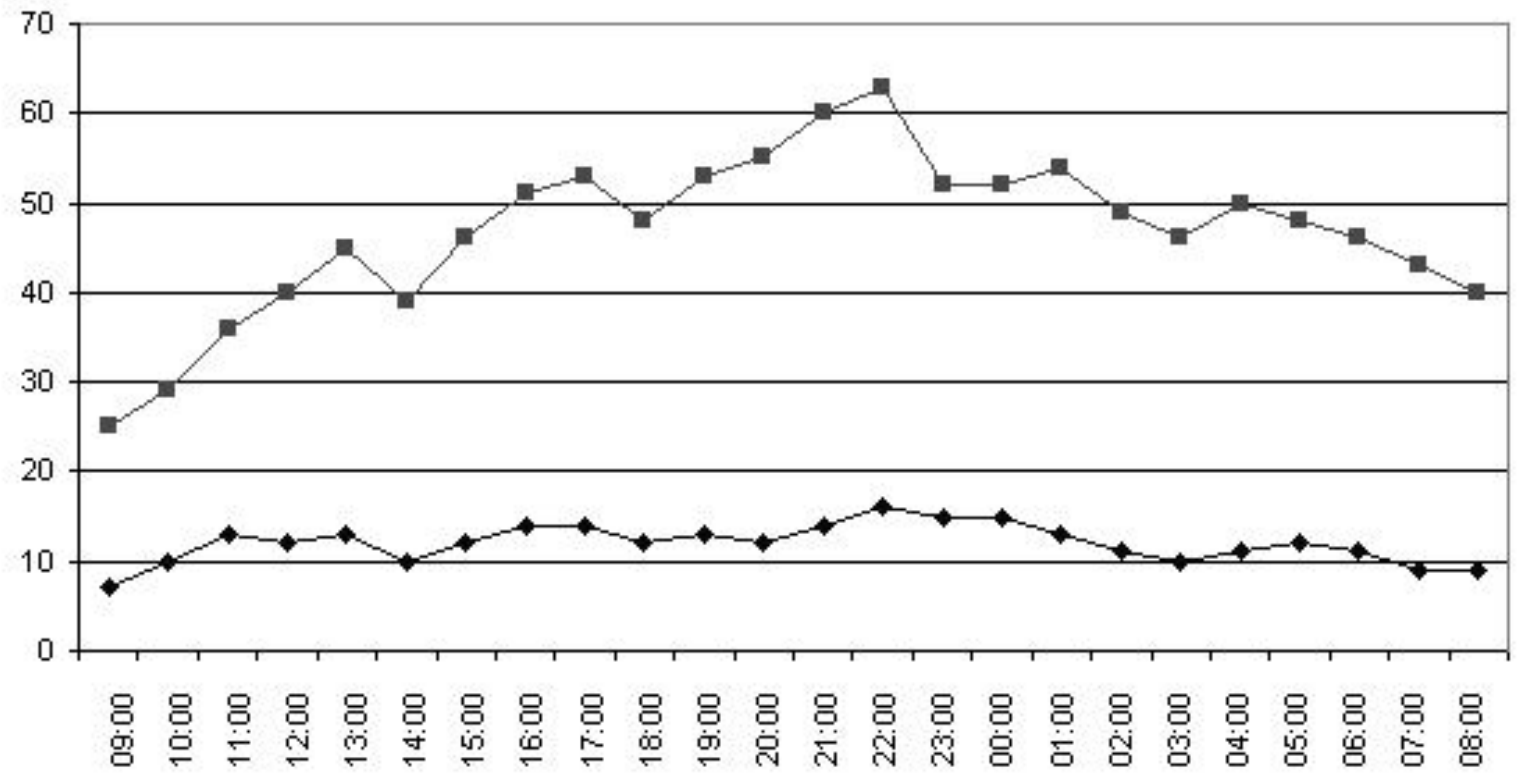

Figura 5b - Variação nictemeral da DBO e DQO no efluente e a montante e jusante de seu ponto de lançamento.

Fonte: Dados de pesquisa. 
Variação nictemeral de parâmetros físico-químicos...

\section{Montante}

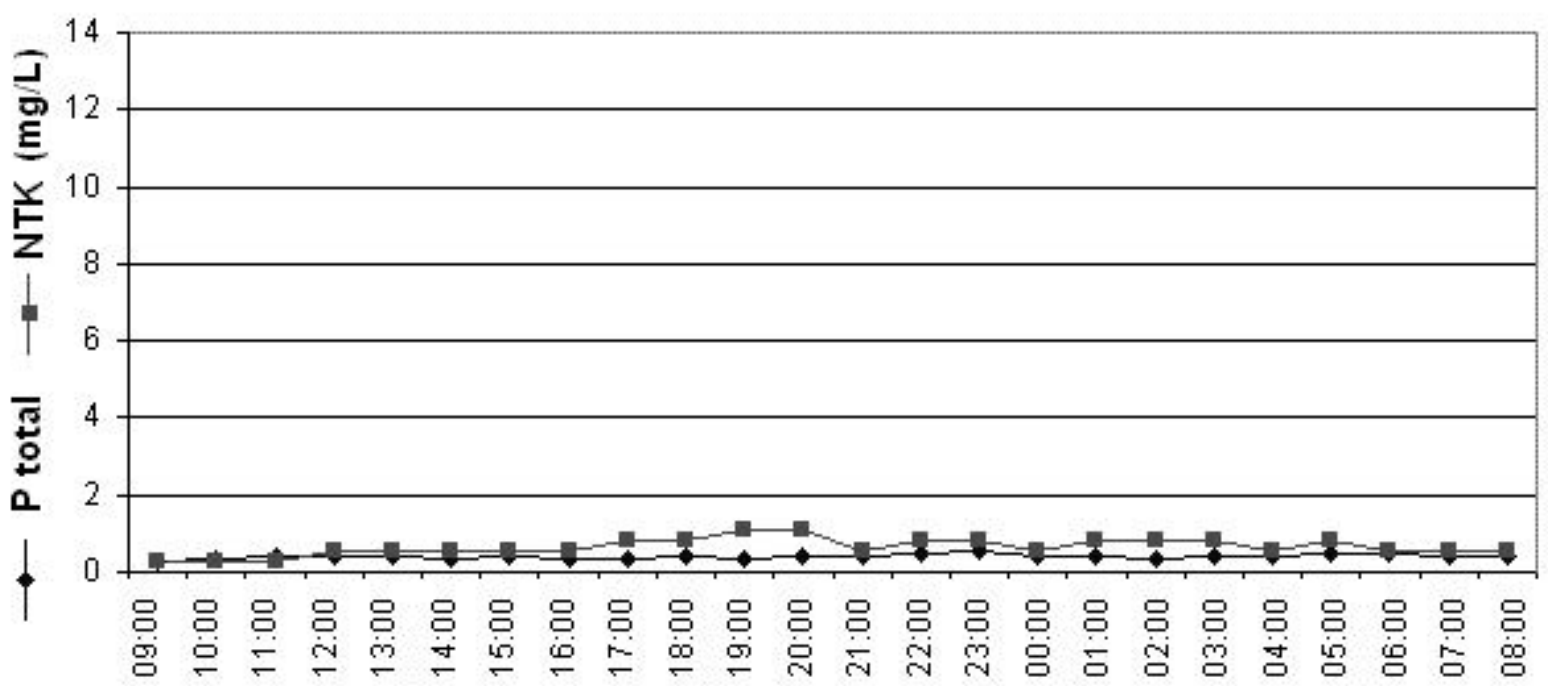

\section{Jusante}

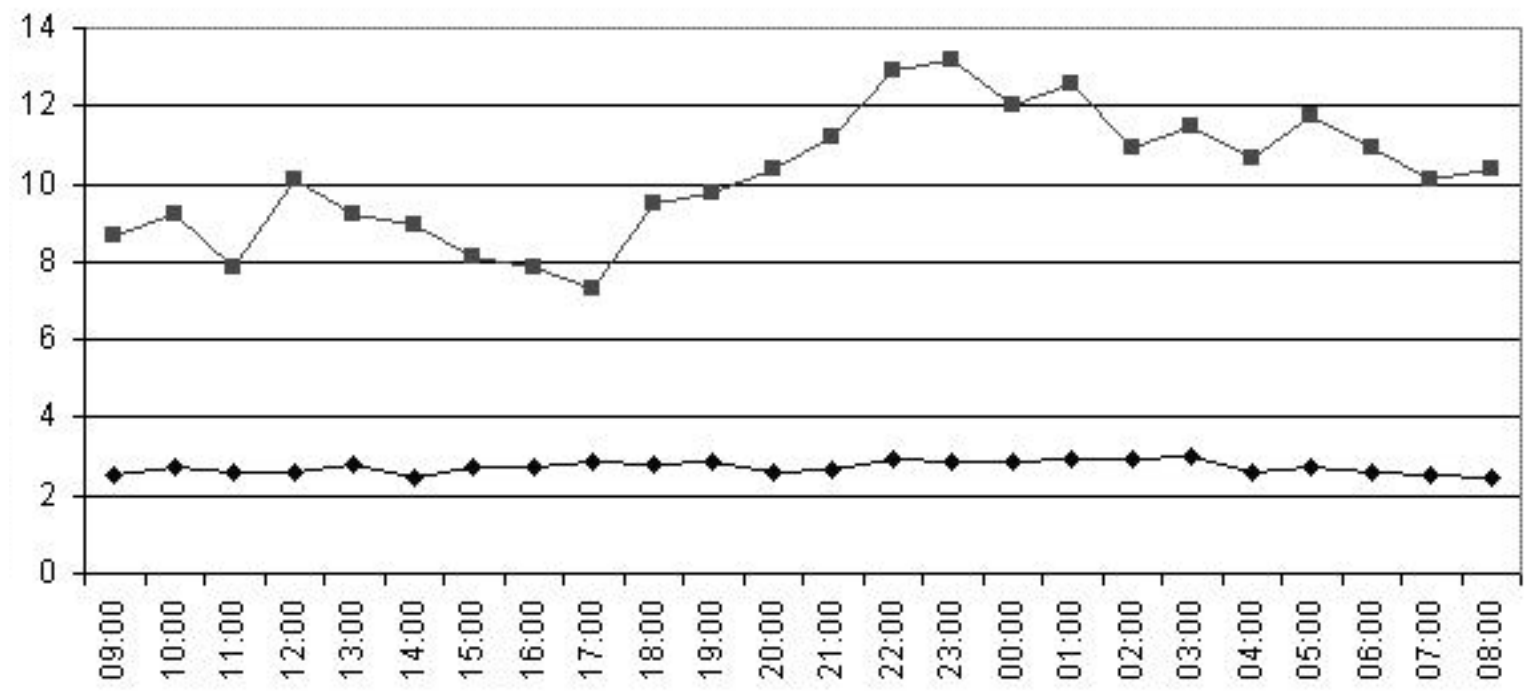

Figura 6 - Variação nictemeral das concentrações de Fósforo Total e Nitrogênio Total Kjeldahl (NTK), a montante e jusante do ponto de lançamento do efluente.

Fonte: Dados de pesquisa. 


\section{Montante}

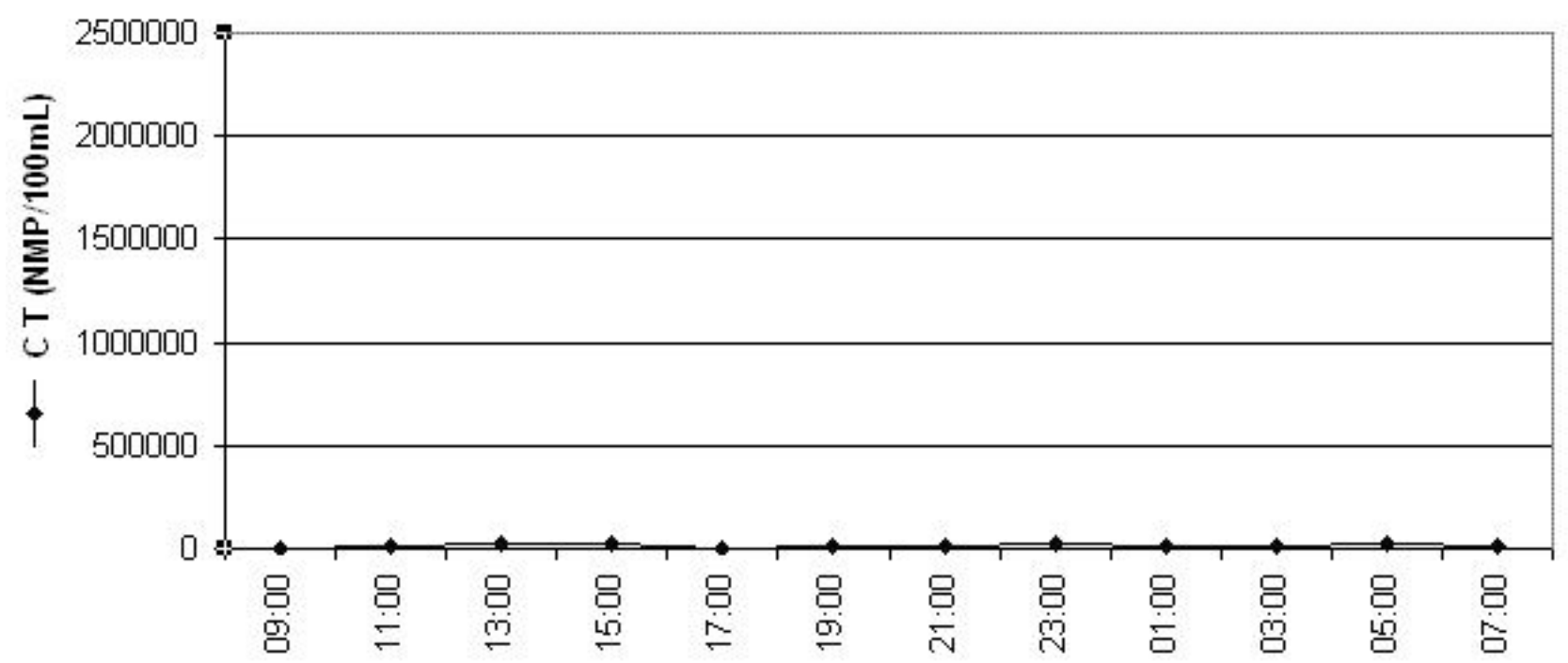

Jusante

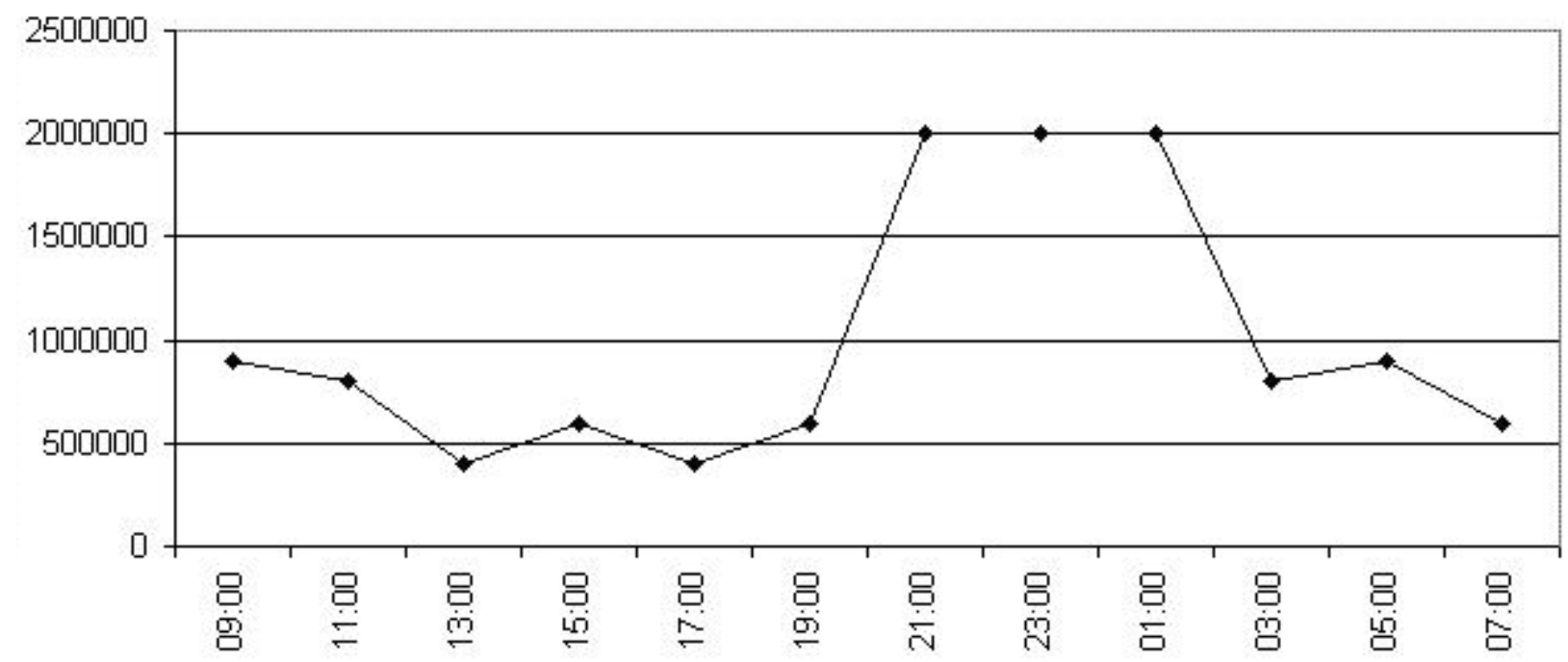

Figura 7 - Variação nictemeral das concentrações de coliformes totais e fecais, a montante e jusante do ponto de lançamento do efluente.

Fonte: Dados de pesquisa. 